\title{
Relationship between Structure and Antigenicity of 01 Vibrio cholerae Lipopolysaccharides
}

\author{
By KAZUHITO HISATSUNE, * MASAHIRO HAYASHI, YUJI HAISHIMA \\ AND SEIICHI KONDO \\ Department of Microbiology, School of Pharmaceutical Sciences Josai University, Sakado, \\ Saitama 350-02, Japan
}

(Received 6 December 1988; revised 7 April 1989; accepted 10 April 1989)

\begin{abstract}
The relationship between the release of fructose from $\mathrm{Ol}$ Vibrio cholerae lipopolysaccharides (LPS) by dilute acetic acid hydrolysis and the decrease in their antigenicity was examined. Decrease in the antigenicity of LPS was not parallel with the release of fructose, and occurred very much later than the latter. Periodate oxidation of LPS resulted in the total elimination of the fructose and glucose, and two-thirds of the heptose constituents, but no difference in the antigenicity of LPS was observed before and after oxidation. These findings indicate that the fructose present in $\mathrm{Ol} V$. cholerae LPS is not substantially involved in their specific antigenicity. In the $\mathrm{O} 1 V$. cholerae LPS, the fructose is in the branch structure, most probably in the core region.
\end{abstract}

\section{INTRODUCTION}

A large variety of neutral and amino sugars are present as components in lipopolysaccharides (LPS) of Gram-negative bacteria. However, the neutral sugar fructose occurs only rarely as an LPS component (Wilkinson, 1977; Kenne \& Lindberg, 1983). Recently, a fructose-containing polysaccharide was reported to exist in the capsular K4 antigen of Escherichia coli O5:K4:H4 (Rodriguez et al., 1988). In a previous study, we demonstrated that, among the vibrios studied, O1 Vibrio cholerae was the only group for which all strains contained fructose in LPS (Kondo et al., 1988).

The role of fructose in the serology of LPS of $\mathrm{O} 1 \mathrm{~V}$. cholerae is of interest. Since heating of $\mathrm{O} 1$ $V$. cholerae LPS in dilute acetic acid at $100^{\circ} \mathrm{C}$ results in release of fructose from LPS and concomitant loss of their antigenicity, it has been suspected that fructose is essentially involved in the antigenicity of LPS of this vibrio (Redmond \& Korsch, 1973). On heating of LPS of most Gram-negative bacteria, free 2-keto-3-deoxyoctonate (KDO), a characteristic sugar constituent of LPS, is released. However, when $\mathrm{O} 1 \mathrm{~V}$. cholerae LPS is treated in this way, release of KDO does not occur; instead, fructose is released. In the LPS molecules of most Gram-negative bacteria, KDO connects the polysaccharide portion and lipid A, and it has been suggested that in the LPS molecule of $\mathrm{O} 1 \mathrm{~V}$. cholerae, KDO in this position may be replaced by fructose (Jann $e t$ al., 1973). However, results obtained by Kaca et al. (1986), studying the effect of removal of D-fructose on the antigenicity of LPS from a rough mutant of $V$. cholerae Ogawa, indicated that D-fructose does not link the polysaccharide and lipid A portion, but that fructose is present as a branch. It was further shown by passive haemolysis inhibition that the release of D-fructose paralleled the exposure of a new common antigenic determinant (Brade \& Galanos, 1983a, $b$ ) cryptic in LPS.

In the present study, the relationship between the release of fructose from $01 \mathrm{~V}$. cholerae LPS by dilute acetic acid hydrolysis and the decrease in their antigenicity was examined using LPS

Abbreviations: DPS, degraded polysaccharide; KDO, 2-keto-3-deoxyoctonate (3-deoxy-D-manno-2-octulosonic acid; PHI, passive haemolysis inhibition. 
isolated from $\mathrm{O} 1 \mathrm{~V}$. cholerae NIH 41 (Ogawa) and 596B (Inaba). In addition, periodate oxidation of both LPS was carried out to determine the effect on antigenicity of removal of the fructose residue of LPS.

\section{METHODS}

Bacterial strains and growth conditions. The strains of O1 V. cholerae, NIH 41 (Ogawa) and 569B (Inaba), were provided by Dr N. Ohtomo, Chemo-Sero-Therapeutic Institute, Kumamoto, Japan. They were cultivated in nutrient broth (pH 7.8) at $37^{\circ} \mathrm{C}$ for $16 \mathrm{~h}$. After killing by heating at $120^{\circ} \mathrm{C}$ for $20 \mathrm{~min}$, cells were harvested and washed with distilled water by centrifugation, and then acetone-dried.

Preparation of LPS. LPS were isolated and purified from acetone-dried cells by the standard phenol/water technique of Westphal et al. (1952).

Analytical methods. Neutral sugars except for fructose were analysed by gas-liquid chromatography (GLC) (column: $3 \%$ ECNSS-M, Gasukuro-kogyo, $3 \mathrm{~mm} \times 2 \mathrm{~m}$ ) as alditol acetate derivatives after hydrolysis in $2 \mathrm{M}$ trifluoroacetic acid at $120^{\circ} \mathrm{C}$ for $1 \mathrm{~h}$. Fructose, as the $O$-acetyl- $O$-methyloxime derivative after hydrolysis in $5 \%$ (v/v) acetic acid at $100^{\circ} \mathrm{C}$ for $2 \mathrm{~h}$, was analysed by GLC using the same column (Hisatsune \& Kondo, 1980). Xylose was used as internal standard. Amino sugars except perosamine were analysed by GLC (column: TABSORB, Regis Chemical Co., $3 \mathrm{~mm} \times 2 \mathrm{~m}$ ) as $\mathrm{N}$-acetylated-O-acetylalditol acetate derivatives after hydrolysis in a $4 \mathrm{M}-\mathrm{HCl}$ at $100^{\circ} \mathrm{C}$ for $8 \mathrm{~h}$. For the analysis of perosamine, samples were hydrolysed in $10 \mathrm{M}-\mathrm{HCl}$ at $90^{\circ} \mathrm{C}$ for $15 \mathrm{~min}$, and then analysed by the same method. Neutral and amino sugars were identified on the basis of their retention times on GLC and their mass spectra in GC/MS analysis compared with those of authentic standards. Heptose was determined either by the method of Osborn (1963) or by GLC. Standard L-glycero- and D-glycero-Dmannoheptose were prepared as described by Bagdian et al. (1966). KDO was estimated by the method of Weissbach \& Hurwitz (1959). Degraded polysaccharide (DPS) was prepared from the supernatant of a weak-acid hydrolysate $\left(5 \%\right.$ acetic acid, $\left.100^{\circ} \mathrm{C}, 3 \mathrm{~h}\right)$ of LPS (Hisatsune et al., 1985). Gel chromatography was performed with Sephadex G-50 and G-10 columns $(1.6 \times 100 \mathrm{~cm})$ using pyridine/acetic acid/water $(10: 4: 1000$, by vol. $)$ as eluent at a flow rate of $1.3 \mathrm{ml} \mathrm{h}^{-1}$.

Periodate oxidation. Periodate oxidation was allowed to proceed for $120 \mathrm{~h}$ in darkness at about $22^{\circ} \mathrm{C}$ with sodium metaperiodate ( $250 \mathrm{mg}$ LPS per $100 \mathrm{ml} 70 \mathrm{~mm}-\mathrm{NaIO}_{4}$ ) and under constant magnetic stirring (Chaby \& Szabo, 1975). An excess of $\mathrm{NaBH}_{4}$ in water was then added and the stirring continued for another $5 \mathrm{~h}$. The solution was dialysed against distilled water and then lyophilized in order to obtain oxidized-reduced LPS.

Serological methods. Antisera against Ogawa and Inaba strains were prepared by immunizing rabbits with heatkilled whole cells of each strain (Shimada \& Sakazaki, 1973). Factor sera A, B and C of O1 V. cholerae were provided by Drs T. Shimada and R. Sakazaki, National Institute of Health, Tokyo. The passive haemolysis inhibition (PHI) test was carried out by using LPS as inhibitor and a passive haemolysis system consisting of sheep red blood cells sensitized with either Ogawa or Inaba LPS, antisera and guinea-pig complement (Hisatsune et al., 1978).

\section{RESULTS AND DISCUSSION}

\section{Release of fructose from LPS and reduction in their antigenicity}

In the LPS molecule of O1 V. cholerae, the fructose component is linked to an unknown position through a fructo-ketosidic linkage which is easily split by heating in dilute acetic acid at $100{ }^{\circ} \mathrm{C}$, resulting in the release of free fructose in the hydrolysate. Fig. 1 shows the release of fructose from Ogawa LPS by heating in $0.5 \%$ or $5 \%$ acetic acid at $100{ }^{\circ} \mathrm{C}$ and the change in LPS antigenicity as assayed by the PHI test at various times of heating.

In the hydrolysis in $5 \%$ acetic acid, the release of fructose reached more than $80 \%$ within about $10 \mathrm{~min}$, and was complete within $30 \mathrm{~min}$, while in $0.5 \%$ acetic acid, it was complete within $90 \mathrm{~min}$. However, the decrease in the antigenicity of LPS did not parallel the increase in fructose release, in either hydrolysis condition. Heating LPS in $5 \%$ acetic acid for $30 \mathrm{~min}$ resulted in almost complete release of fructose, whereas the product still exerted inhibition in the PHI test to the same extent as intact LPS. In order to abolish the antigenicity of LPS completely, about $4 \mathrm{~h}$ heating at $100{ }^{\circ} \mathrm{C}$ was needed regardless of the concentration $(0.5 \%$ or $5 \%$ ) of acetic acid used.

The same results as above were observed with experiments using factor sera $\mathrm{A}$ and $\mathrm{B}$ of $\mathrm{O} 1 \mathrm{~V}$. cholerae instead of the whole-cell antiserum (Fig. 2). Virtually no difference was observed between the curves of the decrease in the antigenicity as assayed by using factor sera A and $B$ of O1 V. cholerae. 


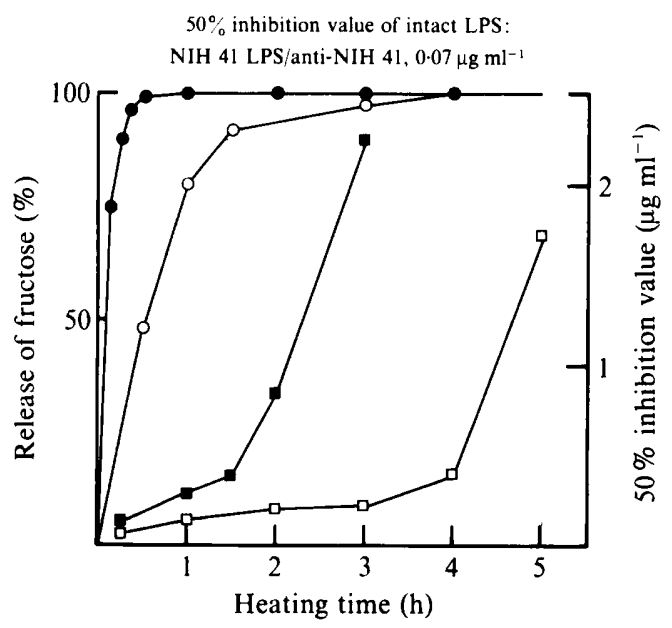

Fig. 1. Release of fructose from O1 $V$. cholerae NIH 41 (Ogawa) LPS by heating in $0.5 \%$ and $5 \%$ acetic acid at $100{ }^{\circ} \mathrm{C}$ and the change in their reactivity with anti-NIH 41 (Ogawa) whole-cell antiserum as assayed by the PHI test. Fructose released by heating in $0.5 \%(O)$ and $5 \%(O)$ acetic acid was determined by the decrease in the fructose content of the heated LPS and is expressed as a percentage of the total content in the intact LPS. The serological activities of the LPS after heating in $0.5 \%(\square)$ and $5 \%(\square)$ acetic acid were determined by the PHI test using the heated LPS as inhibitor and a haemolytic system consisting of sheep red blood cells sensitized with NIH 41 (Ogawa) LPS, anti-NIH 41 (Ogawa) whole-cell antiserum (rabbit) and guinea-pig complement. The serological activities were expressed as the concentration of LPS $\left(\mu \mathrm{g} \mathrm{ml}^{-1}\right)$ which caused $50 \%$ inhibition of the passive haemolysis.

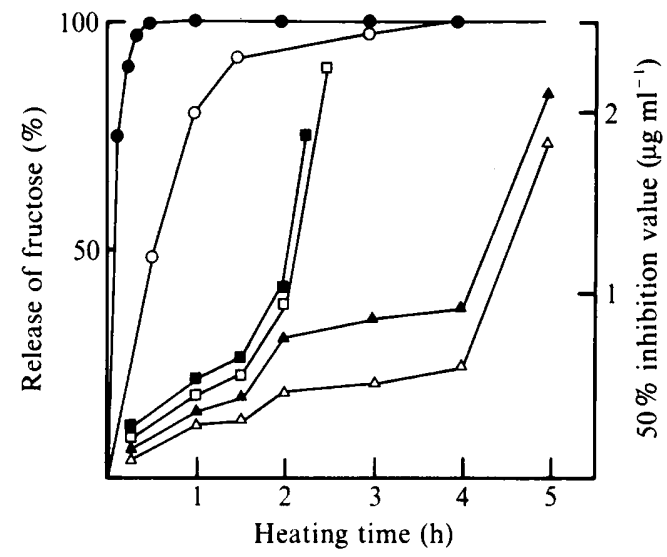

Fig. 2. Release of fructose from O1 V.cholerae NIH 41 (Ogawa) LPS by heating in $0.5 \%$ and $5 \%$ acetic acid at $100{ }^{\circ} \mathrm{C}$ and the change in their reactivity with factor sera $\mathrm{A}$ and B (Ogawa factor) of O1 $\mathrm{V}$. cholerae as assayed by the PHI test. Fructose released by heating in $0.5 \%(O)$ and $5 \%(O)$ acetic acid was estimated as described in the legend to Fig. 1 . The reactivities of the LPS heated in $0.5 \%$ acetic acid against factor sera $A(\Delta)$ and $B(\triangle)$ and of the LPS heated in $5 \%$ acetic acid against factor sera $A(\square)$ and $B(\square)$ were determined by the PHI test as described in the legend to Fig. 1, using factor sera A and B (rabbit) instead of anti-NIH 41 (Ogawa) whole-cell antiserum in the passive haemolysis system.

Results virtually identical to those for Ogawa LPS were obtained using Inaba LPS and antiInaba whole-cell antiserum or factor sera. Since, for unknown reasons, factor serum $\mathrm{C}$ of $\mathrm{Ol} V$. cholerae did not cause significant passive haemolysis of either Ogawa-LPS-sensitized or InabaLPS-sensitized sheep red blood cells, the PHI test using factor serum C was omitted. 
Thus, these results led to the contention that the fructose component present in LPS molecules of $\mathrm{O} 1 \mathrm{~V}$. cholerae LPS is not substantially associated with their antigenicity. This was proved to be true by chemical modification of LPS by periodate oxidation and subsequent analysis of the chemically modified LPS and the examination of their antigenicity, as described below.

\section{Effect of periodate oxidation on chemical structure of LPS}

We examined the structural change in $\mathrm{O} 1 \mathrm{~V}$. cholerae LPS molecules caused by periodate oxidation and subsequent $\mathrm{NaBH}_{4}$ reduction. The sugar composition of intact and chemically modified Ogawa and Inaba LPS is presented in Table 1 . The values shown are molar ratios calculated on the assumption that 3 moles of heptose are contained in intact LPS. Both Ogawa and Inaba LPS contained glucose, fructose, glucosamine, perosamine, quinovosamine and heptose; their molar ratios in these two intact LPS were virtually identical. As compared to intact LPS, in periodate-oxidized and borohydride-reduced Ogawa and Inaba LPS both the fructose and glucose components almost entirely disappeared and about $80 \%$ of the heptose residues were lost. This result is compatible with that of Kaca et al. (1986) for the effect of periodate oxidation on LPS from the rough mutant of $V$. cholerae Ogawa. However, the amounts of perosamine and quinovosamine, both constituting the $\mathrm{O}$-specific polysaccharide side-chain of $\mathrm{O} 1 \mathrm{~V}$. cholerae LPS, and glucosamine, constituting the lipid A backbone, were essentially unchanged. Thus, by periodate oxidation and subsequent reduction it became possible to examine the antigenicity of chemically modified $01 \mathrm{~V}$. cholerae LPS free of fructose.

Mild hydrolysis of Gram-negative bacterial LPS in dilute acetic acid splits the ketosidic linkage between KDO residues and lipid A, resulting in the release of so called Freeman's 'degraded polysaccharide' (DPS) (Freeman, 1942) containing free-form KDO. In the case of O1 $V$. cholerae, LPS are also separated into lipid A and DPS by the same hydrolysis, but, in this case, fructose is released instead of KDO.

In the elution profiles of 'DPS' of either Ogawa or Inaba LPS in Sephadex G-50 gel chromatography using pyridine/acetate buffer ( $\mathrm{pH} 7.0)$ as eluent (Hisatsune et al., 1985), typically three peaks are observed: the first peak (fraction I) corresponds to the polymeric Opolysaccharide side chain, namely an $\alpha(1 \rightarrow 2)$-linked homopolymer of perosamine, with the attached core stubs, the second peak (fraction II) to the core oligosaccharide, and the third peak (fraction III) to low-molecular-mass fragments, namely fructose and inorganic phosphate. Sephadex G-50 gel filtration of 'DPS' prepared from either Ogawa or Inaba 'oxidized LPS' was carried out. Only two fractions were eluted; these probably correspond to fractions I and III for the 'DPS' from intact LPS. Since fraction III had a broad shoulder in its elution front, it was further separated into two fractions by Sephadex G-10 gel chromatography; the fraction eluted first was tentatively referred to as fraction II, and that eluted in the second peak as fraction III in the case of oxidized LPS. The results of compositional analysis of each of these fractions are presented in Table 1. The analytical data represent molar ratios relative to 3 moles of heptose in intact LPS. The analytical data for fraction II, which represents the sugar composition of the core oligosaccharide of the LPS molecule, indicate that the core of intact LPS of O1 V. cholerae consists of 1 mole of glucose, $0 \cdot 1-0 \cdot 2$ mole of glucosamine and 3 moles of heptose. Small amounts of glucosamine were also found in the core of LPS from O1 V. cholerae P1418 Ogawa and its Inaba mutant (Hisatsune et al., 1985). Recently, Kaca et al. (1988) isolated and identified a disaccharide, methyl-7-O-(2-amino- $\alpha$-D-glucopyranosyl)-L-glycero-D-mannoheptose, as a constituent of LPS from three strains of $V$. cholerae. It is therefore considered that the $0 \cdot 1-0 \cdot 2$ mole glucosamine per 3 moles of heptose found in the core of LPS is derived from this disaccharide, which is probably located in the core region of the LPS molecule. In contrast to intact LPS, however, in fraction II from DPS of oxidized LPS of Ogawa and Inaba strains, glucose and glucosamine were entirely missing and only 0.6 mole of heptose was found, indicating that periodate oxidation of intact LPS destroyed the glucose and glucosamine and 2 or more of the 3 moles of heptose originally contained in the core of the intact LPS.

Thus, periodate oxidation of O1 $V$. cholerae LPS removed the fructose and glucose components, but resulted in virtually no structural change in the $\mathrm{O}$-polysaccharide chain, in particular, its $\alpha(1 \rightarrow 2)$-linked homopolymer of perosamine. 
Table 1. Sugar composition (molar ratios) of intact LPS, periodate-oxidized borohydride-reduced $\left(\mathrm{IO}_{4}^{-} \mathrm{OR}\right.$ ) LPS and each DPS fraction isolated from O1 V. cholerae NIH 41 (Ogawa) and 569B (Inaba)

KDO was not detectable by the conventional Weissbach periodate/thiobarbituric acid test under conventional hydrolysis conditions in any of the LPS or DPS preparations examined.

$$
\text { Glucose Fructose Heptose Glucosamine Perosamine Quinovosamine }
$$

LPS

\begin{tabular}{|c|c|c|c|c|c|c|}
\hline NIH 41 intact & $2 \cdot 6$ & $2 \cdot 1$ & $3 \cdot 0$ & 1.8 & 3.6 & 0.3 \\
\hline $\mathrm{NIH} 41 \mathrm{IO}_{4}^{-} \mathrm{OR}$ & - & - & 0.5 & 1.7 & $3 \cdot 1$ & 0.2 \\
\hline 569B intact & $2 \cdot 2$ & $2 \cdot 0$ & $3 \cdot 0$ & 1.8 & 3.5 & $0 \cdot 2$ \\
\hline $569 \mathrm{~B} \mathrm{IO}_{4}^{-} \mathrm{OR}$ & - & - & 0.6 & 1.7 & $3 \cdot 4$ & 0.2 \\
\hline \multicolumn{7}{|l|}{$\begin{array}{l}\text { PS fractions } \\
\text { raction I }\end{array}$} \\
\hline NIH 41 intact & $1 \cdot 7$ & - & $3 \cdot 0$ & $0 \cdot 1$ & $12 \cdot 5$ & 0.5 \\
\hline $\mathrm{NIH} 41 \mathrm{IO}_{4}^{-} \mathrm{OR}$ & - & - & 0.2 & - & $11 \cdot 2$ & 0.4 \\
\hline $569 \mathrm{~B}$ intact & 1.4 & - & $3 \cdot 0$ & 0.3 & $6 \cdot 1$ & 0.6 \\
\hline $569 \mathrm{~B} \mathrm{IO}_{4}^{-} \mathrm{OR}$ & - & - & $0 \cdot 1$ & - & $5 \cdot 7$ & 0.3 \\
\hline \multicolumn{7}{|l|}{ raction II } \\
\hline NIH 41 intact & $1 \cdot 3$ & - & $3 \cdot 0$ & $0 \cdot 1$ & - & \\
\hline $\mathrm{NIH} 41 \quad \mathrm{IO}_{4}^{-} \mathrm{OR}$ & - & - & 0.7 & - & 0.1 & $0 \cdot 2$ \\
\hline 569B intact & $1 \cdot 1$ & - & $3 \cdot 0$ & 0.2 & - & \\
\hline $569 \mathrm{~B} \mathrm{IO}_{4}^{-} \mathrm{OR}$ & - & - & 0.6 & - & 0.3 & $0 \cdot 2$ \\
\hline \multicolumn{7}{|l|}{ raction III } \\
\hline NIH 41 intact & - & $++t$ & - & - & - & \\
\hline $\mathrm{NIH} 41 \mathrm{IO}_{4}^{-} \mathrm{OR}$ & - & - & - & - & - & - \\
\hline $569 \mathrm{~B}$ intact & - & +++ & - & - & - & - \\
\hline $569 \mathrm{~B} \mathrm{IO}_{4}^{-} \mathrm{OR}$ & - & - & - & - & - & \\
\hline
\end{tabular}

Table 2. Reactivity in the PHI test of intact LPS and periodate-oxidized borohydride-reduced $\left(\mathrm{IO}_{4}^{-} \mathrm{OR}\right) \mathrm{LPS}$ isolated from Ol V. cholerae NIH 41 (Ogawa) and 569B (Inaba)

The results are expressed as the concentration of LPS $\left(\mu \mathrm{g} \mathrm{ml}^{-1}\right)$ required to give $50 \%$ inhibition of passive haemolysis. SRBC, sheep red blood cells.

\begin{tabular}{|c|c|c|c|c|c|}
\hline \multirow[b]{3}{*}{ Inhibitor LPS } & \multicolumn{5}{|c|}{ Passive haemolysis system (SRBC sensitized with LPS/antiserum) } \\
\hline & \multicolumn{3}{|c|}{ NIH 41 Ogawa } & \multicolumn{2}{|c|}{ 569B Inaba } \\
\hline & $\begin{array}{l}\text { NIH } 41 \text { LPS/ } \\
\text { anti-NIH } 41\end{array}$ & $\begin{array}{l}\text { NIH } 41 \text { LPS/ } \\
\text { anti-A }\end{array}$ & $\begin{array}{l}\text { NIH } 41 \text { LPS/ } \\
\text { anti-B }\end{array}$ & $\begin{array}{c}\text { 569B LPS/ } \\
\text { anti-569B }\end{array}$ & $\begin{array}{l}\text { 569B LPS/ } \\
\text { anti-A }\end{array}$ \\
\hline NIH 41 intact & $0 \cdot 19$ & $0 \cdot 27$ & $0 \cdot 11$ & $0 \cdot 28$ & NT \\
\hline NIH $41 \mathrm{IO}_{4}^{-} \mathrm{OR}$ & $0 \cdot 22$ & $0 \cdot 22$ & $0 \cdot 15$ & $0 \cdot 32$ & NT \\
\hline $569 \mathrm{~B}$ intact & 210 & NT & NT & 0.28 & 0.05 \\
\hline $569 \mathrm{~B} \mathrm{IO}-\mathrm{OR}$ & 790 & NT & NT & $0 \cdot 31$ & 0.08 \\
\hline
\end{tabular}

\section{Antigenicity of periodate-oxidized LPS}

The effect of periodate oxidation on the antigenicity of intact LPS of O1 V. cholerae was determined by means of the PHI test (Table 2). Ogawa intact LPS exerted strong inhibition in the homologous Ogawa/anti-Ogawa system; the concentration producing $50 \%$ inhibition was $0 \cdot 19 \mu \mathrm{g} \mathrm{ml}^{-1}$. Ogawa intact LPS also exerted strong inhibition in the heterologous Inaba/antiInaba system, to the same extent as it did in the homologous Ogawa system. In contrast to Ogawa intact LPS, Inaba intact LPS exerted strong inhibition in the homologous Inaba system, but very weak inhibition in the heterologous Ogawa system (Table 2). This result is consistent with the conventional ABC concept of the O-antigenic structure of O1 V.cholerae (Sakazaki \& Tamura, 1971 ; Finkelstein, 1973), i.e. it consists of three antigen factors, major group antigen A, 
antigens $\mathrm{B}$ (Ogawa factor) and $\mathrm{C}$ (Inaba factor), and among $\mathrm{O} 1 \mathrm{~V}$. cholerae, two antigenic forms designated Ogawa and Inaba, with antigenic formulae $\mathrm{AB}(\mathrm{c})$ and $\mathrm{AC}$, respectively, are recognized.

The PHI test for oxidized LPS was also carried out using factor sera A and B of O1 V. cholerae instead of the whole-cell antisera (Table 2). Strong and equivalent inhibition was exerted by either Ogawa intact or oxidized LPS in both Ogawa/anti-A and Ogawa/anti-B systems. Also, strong and equivalent inhibition was exerted by either Inaba intact or oxidized LPS in the Inaba/anti-A system (Table 2). Thus, in these PHI analyses, no difference was observed between the antigenicity of oxidized and intact $\mathrm{O} 1 \mathrm{~V}$. cholerae LPS, leading to the conclusion that the oxidized LPS which are free of fructose possess the same degree of antigenicity as the intact LPS. Consequently the fructose component present in O1 $V$. cholerae LPS is not substantially involved in their $\mathrm{O}$-antigenicity.

It has been postulated that the fructose component in the LPS molecules of $\mathrm{O} 1 \mathrm{~V}$. cholerae connects the polysaccharide portion and lipid A (see Introduction). However, our preliminary results indicate that this is not the case. When Ogawa or Inaba LPS were treated in $5 \%$ acetic acid at $100{ }^{\circ} \mathrm{C}$ for $30 \mathrm{~min}$, all the fructose was released. The hydrolysate was dialysed against distilled water, and the retentate and diffusate were lyophilized separately. No fructose was detected in the retentate and it was almost quantitatively recovered in the diffusate. No precipitate of lipid A was observed in the acetic acid solution after this hydrolysis, indicating that the linkage between the inner core region and lipid A of LPS was not cleaved. These results are considered to be compatible with the interpretation that the polysaccharide portion is not connected to lipid A through fructose in the LPS molecules of O1 V. cholerae. Kaca et al. (1986) suggested recently that the fructose component is present as a branch in the LPS molecule of this vibrio.

Dr Toshio Shimada, National Institute of Health, Tokyo, is particularly acknowledged for his courtesy in providing us factor sera $\mathrm{A}, \mathrm{B}$ and $\mathrm{C}$ of $\mathrm{Ol} V$. cholerae.

\section{REFERENCES}

Bagdian, G., Droge, W., Kotelko, K., Luderitz, O. \& WestPHAL, O. (1966). Vorkommen zweier Heptosen in Lipopolysacchariden enterobacterieller Zellwande: L-glycero- und D-glycero-D-mannoheptose. Biochemische Zeitschrift 344, 197-211.

Brade, H. \& Galanos, C. (1983a). A new lipopolysaccharide antigen identified in Acinetobacter calcoaceticus: occurrence of widespread natural antibody. Journal of Medical Microbiology 16, 203-210.

Brade, H. \& Galanos, C. (1983b). Common lipopolysaccharide specificity: new type of antigen residing in the inner core region of S- and R-form lipopolysaccharides from different families of gram-negative bacteria. Infection and Immunity 42, 250-256.

CHABY, R. \& SzABO, L. (1975). 3-Deoxy-2-octulosonic acid 5-phosphate: a component of the endotoxin of Bordetella pertussis. European Journal of Biochemistry 59, 277-280.

Finkelstein, R. A. (1973). Cholera. CRC Critical Reviews in Microbiology 2, 553-623.

FreEMAN, G. G. (1942). The preparation and properties of a specific polysaccharide from Bact. typhosum Ty2. Biochemical Journal 36, 340-355.

HisATSUNE, K. \& Kondo, S. (1980). Lipopolysaccharides of $\mathbf{R}$ mutants isolated from Vibrio cholerae. Biochemical Journal 185, 77-81.

Hisatsune, K., Kondo, S. \& Kobayashi, K. (1978). Lipopolysaccharides of Vibrio cholerae. (II). An immunochemical study on O-antigenic structure. Japanese Journal of Medical Science and Biology 31, 181-184.
Hisatsune, K., Yamamoto, F. \& Kondo, S. (1985). Lipopolysaccharide of Vibrio cholerae: chemical and serological properties. In Advances in Research on Cholera and Related Diarrheas, pp. 17-24. Edited by S. Kuwahara \& N. F. Pierce. Tokyo: KTK Scientific Publishers.

JANN, B., JANN, K. \& BeYAERT, G. O. (1973). 2-Amino2,6-dideoxy-D-glucose (D-quinovosamine): a constituent of the lipopolysaccharides of Vibrio cholerae. European Journal of Biochemistry 37, 531-534.

KaCA, W., Brade, L., RieTschel, E. T. \& Brade, H. (1986). The effect of removal of D-fructose on the antigenicity of the lipopolysaccharide from a rough mutant of Vibrio cholerae Ogawa. Carbohydrate Research 149, 293-298.

KaCA, W., Jough-LeuveninK, J., Zahringer, U., RIETSCHEL, E. TH. \& BRADE, H. (1988). Isolation and chemical analysis of 7-O-(2-amino-2-deoxy-D-glucopyranosyl)-L-glycero-D-manno-heptose as a constituent of the lipopolysaccharides of the UDP-galactose epimeraseless mutant $J-5$ of Escherichia coli and Vibrio cholerae. Carbohydrate Research 179, 289-299.

KENNE, L. \& LINDBERG, B. (1983). Bacterial polysaccharides. In The Polysaccharides, vol. 2, pp. 287-363. Edited by G. O. Aspinall. New York: Academic Press.

Kondo, S., Iguchi, T. \& Hisatsune, K. (1988). A comparative study of the sugar composition of lipopolysaccharides isolated from Vibrio cholerae, 'Vibrio albensis' and Vibrio metschnikovii. Journal of General Microbiology 134, 1699-1705. 
OSBORN, M. J. (1963). Studies on the gram-negative cell walls. I. Evidence for the role of 2-keto-3-deoxyoctonate in the lipopolysaccharide of Salmonella typhimurium. Proceedings of the National Academy of Sciences of the United States of America 50, 499-506.

REDMOND, J. W. \& KoRSCH, M. J. (1973). Immunochemical studies of the O-antigens of Vibrio cholerae: partial characterization of an acid-labile antigenic determinant. Australian Journal of Experimental Biology and Medical Science 51, 229-235.

RodrigueZ, M. L., JANN, B. \& JANN, K. (1988). Structure and serological characteristics of the capsular $\mathrm{K} 4$ antigen of Escherichia coli $\mathrm{O} 5: \mathrm{K} 4: \mathrm{H} 4$, a fructose-containing polysaccharide with a chondroitin backbone. European Journal of Biochemistry 177, 117-124.

SAKAZAKI, R. \& TAMURA, K. (1971). Somatic antigen variation in Vibrio cholerae. Japanese Journal of Medical Science and Biology 4, 93-100.

Shimada, T. \& SAKaZaKi, R. (1973). R antigen of Vibrio cholerae. Japanese Journal of Medical Science and Biology 26, 155-160.

Weissbach, A. \& HuRwitz, J. (1959). The formation of 2-keto-3-deoxy-heptonic acid in extracts of Escherichia coli B. Journal of Biological Chemistry 234, 705-709.

Westphal, O., Luderitz, O. \& Bister, R. (1952). Uber die Extraction von Bakterien mit Phenol/ Wasser. Zeitschrift für Naturforschung 7b, 148-155.

WILKINSON, S. G. (1977). Composition and structure of bacterial lipopolysaccharides. In Surface Carbohydrates of the Prokaryotic Cell, pp. 97-175. Edited by I. W. Sutherland. New York: Academic Press. 